\title{
EXPERIÊNCIAS DE LEITURA COM A POESIA DE AUGUSTO DOS ANJOS NO ENSINO MÉDIO: CONTRIBUIÇÕES NA FORMAÇÃO DE LEITORES
}

\section{READING EXPERIENCES WITH AUGUSTO DOS ANJOS' POETRY IN HIGH SCHOOL: CONTRIBUTIONS TO READERS DEVELOPMENT}

\author{
Verônica Lucena do Nascimento ${ }^{1}$ \\ José Hélder Pinheiro Alves ${ }^{2}$
}

\begin{abstract}
Resumo: Neste trabalho apresentamos algumas reflexões sobre a leitura literária e suas implicações na formação de leitores a partir da análise de dados da recepção da poesia de Augusto dos Anjos no ensino médio. O estudo é parte da nossa pesquisa de mestrado e expõe os efeitos da lírica augustiana nas experiências de leitura dos alunos participantes. Para tanto, tomamos as discussões de Petit (2013), Aguiar e Bordini (1988), Rezende (2013), Pinheiro (2018), Colomer (2007) e Jauss (1994) dentre outros autores, para discutir questões relativas à leitura literária e à recepção dessa poesia.
\end{abstract}

Palavras-chave: leitura literária; formação de leitores; Augusto dos Anjos; recepção.

Abstract: In this work we present some reflections on literary reading and its implications for the formation of readers from the analysis of data from the reception of Augusto dos Anjos' poetry in high school. The study is part of our master's research and exposes the effects of the Augustinian lyric on the reading experiences of participating students. For that, we took the discussions of Petit (2013), Aguiar and Bordini (1988), Rezende (2013), Pinheiro (2018), Colomer (2007) and Jauss (1994) among other authors, to discuss issues related to literary reading and to the reception of that poetry.

Keywords: literary reading; reader development; Augusto dos Anjos; reception.

\section{Introdução}

1 Graduada em Letras Português pela Universidade Federal de Campina Grande (UFCG) e Mestre em Linguagem e Ensino, com ênfase em Literatura e Ensino pela Universidade Federal de Campina Grande (UFCG). E-mail: veronicalucenna@gmail.com

2 Doutor em Letras pela Universidade de São Paulo (USP) e Pós- doutor pela Universidade de Minas Gerais (UFMG). Atualmente é professor titular em Literatura Brasileira na Universidade Federal de Campina Grande (UFCG), trabalhando principalmente com os temas: literatura e ensino, poesia, literatura infantil e literatura de cordel. Integra o GT Literatura e Ensino da AMPOLL. E-mail: helder.pinalves@gmail.com 
Refletir sobre a leitura literária no contexto da escola brasileira suscita questões que vão desde o acesso ao livro, até a forma como a literatura é abordada na sala de aula. A diversidade de contextos nos quais os jovens estão inseridos nem sempre permite o contato com as obras. As dificuldades de acesso e o pouco interesse dos alunos cada vez mais inseridos no mundo das tecnologias e das suas múltiplas ferramentas de interação, comunicação e entretenimento exigem do professor estratégias de abordagens que favoreçam descobertas e encontros entre texto - leitor.

O pouco interesse dos adolescentes muitas vezes se relaciona à desvinculação da atividade de ler ao prazer, e pode ser explicado pela forma como a literatura é tratada nos espaços escolares, em que os textos são tomados como pretexto para análise linguística, baseada na leitura de fragmentos e no ensino de história da literatura, sob uma perspectiva cronológica. São vários os estudos e pesquisas que apontam esta problemática, como se pode observar em: Dias (2016), Martins (2006), Pinheiro (2006, 2014, 2018), Rezende (2013), Rouxel (2013, 2014), dentre outros autores.

A falta ou ainda insuficiência da experiência estética dificulta o leitor de adentrar no universo do imaginário, da inventividade, da ludicidade, com a polissemia da linguagem literária, que proporciona sedução e prazer contribuindo para a procura de novas leituras.

Quando se trata do contexto do ensino médio, os estudos destacam que as obras são abordadas a partir de informações históricas, com foco nas características principais de autores e de estilos de época, por vezes pautadas pelo livro didático. Muitos escritores são discutidos de forma reduzida, por particularidades que sobressaíram ao longo do tempo, como é o caso, por exemplo, da poesia de Augusto dos Anjos, que normalmente é exposto nos manuais, pelos poemas mais pessimistas, que tratam da morte e renderam estereótipos ao poeta.

Considerando tal problemática, refletimos neste trabalho sobre o ensino de literatura e apresentamos a recepção dos poemas augustianos no terceiro ano do ensino médio de uma escola pública de Campina Grande, (Paraíba). Destacamos aspectos temáticos e de linguagem que repercutiram nas experiências de leituras dos alunos e indicaram possíveis contribuições dessa lírica na formação de leitores. O trabalho é parte de nossa pesquisa de mestrado e sua pertinência é justificada pela necessidade de estudos que investiguem e discutam possíveis colaborações dessa poesia, sob a perspectiva da recepção. 
Além disso, por observamos que embora o poeta tenha notoriedade significativa, sua poesia ainda é pouco lida pelo público, como detectamos por meio de análise das respostas do questionário aplicado na sala de aula, para sondar interesses e preferências de leituras dos participantes.

Os dados apresentados foram adquiridos por gravações de áudio das aulas durante intervenção, mais especificamente da vivência de três antologias temáticas, que reuniam poemas de amor, natureza, vida e morte na poesia augustiana. Nesse artigo nos deteremos à recepção de dois poemas: "Vozes da morte" e "O pântano", que integravam a antologia que tratava da natureza. As categorias de análise adotadas foram: estranhamento, leitura subjetiva, prazer e o riso, pois repercutiram na recepção dos alunos. Procuramos desenvolver um trabalho com atividades e metodologias que privilegiassem a leitura compartilhada, numa perspectiva de valorização da experiência literária.

\section{Ensino de literatura e leitura literária: entre impasses e desafios}

Trabalhar o texto literário na escola em uma perspectiva de formação do leitor nem sempre se mostra uma tarefa fácil na contemporaneidade. Os desafios são muitos, em um contexto social tomado de aparatos tecnológicos que influenciam no comportamento dos jovens e exigem alterações de paradigmas, como explica Martins (2004, p.1112): "Os gêneros literários começam a se adaptar a esse contexto, pois os leitores e os autores parecem priorizar textos curtos (contos, crônicas, poemas), dado o dinamismo da vida moderna".

Os textos mais longos ou mesmo os curtos que apresentam mais complexidade suscitam dificuldades aos professores na busca de estratégias que contribuam no processo de formação de leitores. Obter a atenção das novas gerações nem sempre se torna uma tarefa fácil. De acordo com Martins (2004):

(...) a troca de experiências narrativas estão definhando diante, por exemplo, de formas atrativas de comunicação como os bate-papos virtuais, (Chats), os e-mails, e tantas outras, parece-nos que o aluno dedica-se cada vez menos, à leitura literária, sem que a escola consiga atraí-lo para que desenvolva de forma qualitativa e também quantitativa o ato da leitura. (MARTINS, 2004, p. 1117)

As formas tradicionais de ensino com suas fragilidades já não atendem as expectativas dos jovens contemporâneos. Petit (2013, p. 57), afirma que a relação conflituosa entre leitura 
e escola, por vezes, é causada por experiências que afastam o prazer de ler, atividades que "dissecam os textos, das horríveis fichas de leituras, do jargão, dos programas arcaicos". Embora as reflexões de Petit (2013) sejam sobre o contexto francês, podemos relacioná-lo ao brasileiro, em que ainda verificamos abordagens que nem sempre permitem experiências significativas para os alunos, muitas vezes, pré-determinada pelo livro didático, com o objetivo de resolução de exercícios, que dificultam ou ainda impedem, o ensino e a aprendizagem numa perspectiva mais reflexiva e crítica.

Segundo Dias (2006, p. 212), ainda há o problema de veiculação da literatura a outras áreas do conhecimento, para atribuir sentido a atividade de ler. Ou seja, a leitura literária "parece não constituir parte necessária no processo de formação de leitores se não se associar a um porquê, que está quase sempre fora da literatura". No entanto, essas adversidades também podem ser vistas e enfrentadas como um terreno fértil para a realização de descobertas e trabalhos que favoreçam o interesse pela leitura literária.

As reflexões da estética da recepção e suas considerações sobre o leitor contribuem para pensarmos possibilidades de abordagens com a leitura literária na escola, já que valoriza a participação do sujeito, quando discute os métodos de construir uma história da literatura mais condizente com a recepção dos textos.

Para Jauss (1994), a historiografia literária deveria ser concebida a partir da recepção e efeito das obras no leitor, pois provocava consequências estéticas e históricas:

\begin{abstract}
A implicação estética reside no fato de já a recepção primária de uma obra pelo leitor encerrar uma avaliação de seu valor estético, pela comparação com outras obras já lidas. A implicação histórica manifesta-se na possibilidade de, numa cadeia de recepções, a compreensão dos primeiros leitores ter continuidade e enriquecer-se de geração em geração, decidindo, assim, o próprio significado histórico de uma obra e tornando visível sua qualidade estética. Se, pois, se contempla a literatura na dimensão de sua recepção e de seu efeito, então a oposição entre aspecto estético e seu aspecto histórico vê-se constantemente mediada, e reatado o fio que liga o fenômeno passado à experiência presente da poesia, fio este que o historicismo rompera. (JAUSS, 1994, p. 23)
\end{abstract}

Nessa perspectiva, a historiografia não seria constituída a partir de fatos literários, de forma cronológica e estática, mas como algo sempre experienciável e renovável pela recepção e efeito das obras nas várias comunidades de leitores.

Compagnon (2010, p. 146), explica que os estudos da estética da recepção originários de Ingarden percebiam o texto como um "potencial concretizado pelo leitor", que estabelece relação com o material escrito e atribui sentido às experiências estéticas: 
Quando lemos, nossa expectativa é função do que nós já lemos -, não somente no texto que lemos, mas em outros textos -, e os acontecimentos imprevistos que encontramos no decorrer de nossa leitura obrigam-nos a reformular nossas expectativas e a reinterpretar o que já lemos, tudo que já lemos até aqui neste texto e em outros. A leitura procede, pois, em duas direções ao mesmo tempo, para frente e para trás, sendo que um critério de coerência existe no princípio da pesquisa do sentido e das revisões contínuas pelas quais a leitura garante uma significação totalizante à nossa experiência. (COMPAGNON, 2010, p. 146)

Os textos são ressignificados pela relação com outras experiências textuais, de mundo, de vida, etc. Tais reflexões sobre a participação do leitor colaboram para pensarmos o ensino de literatura pautado em informações históricas sobre autores e obras literárias como eixo primordial de abordagem.

De acordo com Rezende (2013, p. 102), essa perspectiva de ensino toma fatos e informações "como se fosse literatura". As informações historicistas, o contexto das obras e autores substitui a leitura, o debate e a reflexão dos textos que se tornam distante da sala de aula e da vida dos alunos.

As obras não são lidas e trabalhadas na sua complexidade e reflexão, o que dificulta a aproximação entre texto e leitor. Enveredada pelo tradicionalismo, com finalidades específicas de resoluções de exercícios, tira dos alunos o direto de conhecer os saberes culturais abordados na literatura, das leituras sem amarras que favorece o prazer de ler. Para Pinheiro (2012, p. 87):

A metodologia de ensino de literatura pautada na resolução de exercícios pela indicação de obras para provas, mas sem tempo para discussão dos mais diversos elementos presentes nos textos, sem possibilitar o leitor se colocar e expor seu ponto de vista, tem fracassado na formação de leitores. (PINHEIRO, 2012, p. 87)

O ensino de literatura exige do professor uma atitude consciente, crítica e transformadora, pelas possibilidades que oferece de atingir o outro, de refletir a existência e as ações em sociedade. De acordo com Aguiar e Bordini (1988), as especificidades da linguagem literária diferem da linguagem do cotidiano e possibilita o leitor vivenciar experiências que atuam na formação, possibilita vivências singulares e efeitos diversos.

A partir da interação com a obra, da identificação com os personagens, os sujeitos podem ser cativados pela leitura. Nessa perspectiva, é essencial o contato com as obras, uma vez que, além de interferir no íntimo do sujeito, favorece a vivência dos mais diversos sentimentos. Conforme destaca Petit (2013):

O que está em jogo a partir da leitura é a conquista ou reconquista de uma posição de indivíduo. Pois os leitores são ativos, se aproximam do que leem, dão outro 
significado aos textos lidos, deslizam seus desejos, suas fantasias e suas angústias entre as linhas, desenvolvem toda uma atividade mental. Na leitura há algo mais do que o prazer, algo que é da ordem de um trabalho psíquico, no mesmo sentido de quando falamos em trabalho de luto, trabalho de sonho ou trabalho de escrita. Um trabalho psíquico que permite encontrar um vínculo com aquilo que nos constitui, que nos dá vida. (PETIT, 2013, p. 68. Grifos da autora)

São as experiências estéticas que podem sensibilizar o leitor, marcar sua relação com o texto, promover encontros, desencontros, inquietações, interesses, ou seja, mexer com seu íntimo e motivar na procura de outras leituras.

\section{Formação do leitor: entre reflexões e possibilidades de encontros}

Como formar leitores literários no contexto da escola brasileira? Nossa proposta nesse trabalho não é responder essa complexa pergunta, mas refletir sobre o assunto a partir do nosso experimento com a poesia de Augusto dos Anjos no ensino médio.

A formação de leitores não é uma responsabilidade exclusivamente da escola, é algo mais amplo, que depende de vários fatores. A importância da relação precoce com a leitura, por exemplo, pode ser decisiva para um indivíduo e repercutir ao longo da vida. Segundo Petit (2013):

(...) aqueles a quem a mãe contou uma história toda noite têm o dobro da probabilidade de se tornarem grandes leitores do que aqueles que praticamente nunca passaram por essa experiência. A importância de ver os adultos lendo com paixão também se manifesta nos relatos dos leitores. Muitas vezes, nos tornamos um leitor porque vimos um parente, um adulto querido mergulhado nos livros, longe, inacessível, e a leitura aparece como um meio de se aproximar dele e de apropriar-se das qualidades que lhe atribuímos. (PETIT, 2013, p. 35)

No entanto, esse contato com a leitura ainda na infância nem sempre é uma realidade no contexto brasileiro, com suas adversidades financeiras, índices de analfabetismo, dificuldades de acesso aos livros. Políticas públicas de incentivo e distribuição do material escrito passam por retrocessos no Brasil, com projetos importantes de distribuição e estímulo à atividade de ler, interrompidos e até cancelados, (DEBBUS, BAZZO e BORTOLOTTO, 2018). Além disso, há a necessidade de formação de professores e bibliotecários mais adequada que colabore com o processo.

Segundo Tinoco e Sthefani (2016), o papel do professor como agente mediador da leitura na escola tem importância significativa. Nessa perspectiva há a imprescindibilidade dos educadores serem leitores de textos literários, demonstrarem intimidade com as obras, 
pois o ato de mediar implica o conhecimento de gêneros, a escolha adequada do material escrito, elaboração de perguntas que favoreçam as discussões, o conhecimento de teorias que auxiliem na escolha de estratégias que valorizem a relação texto- leitor, etc.

Pinheiro (2018), refletindo sobre a relação dos jovens com a poesia, ressalta:

\begin{abstract}
É indispensável pensar metodologias de abordagem tendo em vista cada sala de aula, cada situação nova. Inúmeras vezes, encontramos alunos e alunas que resistem a poemas de Drummond, de Cecília, de Manuel Bandeira. Nessas situações alguns professores agem estranhamente chamando os alunos de burros, de insensíveis... não têm a velha paciência histórica, a consciência de que se o aluno tem dificuldade de gostar de algo é porque se trata de uma coisa a que poucas vezes teve acesso. (PINHEIRO, 2018, p. 113)
\end{abstract}

Em um contexto de resistência à poesia, há necessidade de abordagens que estreite os laços entre leitor- texto. Ou seja, propiciar a leitura de poemas, dialogar, discutir e desvelar os textos conjuntamente com alunos. Além disso, quando temos uma diversidade de públicos, cuja intimidade com os livros nem sempre é algo possível. A importância desse trabalho é fundamental, pois gera mais interesse e gosto pelo ato de ler, que se reflete no decorrer da vida do educando, uma vez que a leitura literária na sua multiplicidade de abordagens proporciona prazer. Como reflete Woolf (2016):

(...) a leitura nos dá prazer. É um prazer complexo e um prazer difícil varia de época e de livro para livro. Mas ele é suficiente. Na verdade, o prazer é tão grande que não se pode ter dúvidas de que sem ele o mundo seria um lugar muito diferente e muito inferior ao que é. Ler mudou, muda e continuará mudando o mundo. (WOOLF, 2016. p.39)

As reflexões de Woolf (2016), no convida a refletir sobre a leitura literária e estratégias de abordagens da literatura na escola que colaborem com a formação de leitores literários. A diversidade de textos favorecem experiências singulares, olhares mais sensíveis para o cotidiano, confirmações da humanidade em si, como defende Candido (2012).

Nesse sentido, não basta só oportunizar tividades de ler. Mas proporcionar um ensino considerando a variedade de gêneros, as especificidades da linguagem literária, os aspectos formais e temáticos dos textos.

A leitura compartilhada das obras pode favorecer a percepção de detalhes, nuances, pontos de vista diversificados. A socialização e o debate estimulam os alunos, mediados pelo professor discutir as singularidades dos textos, as experiências individuais, como explica Colomer (2007):

Compartilhar as obras com as outras pessoas é importante porque torna possível beneficiar-se da competência dos outros para construir o sentido e obter prazer de 
entender melhor os livros. Também porque permite experimentar a literatura em sua dimensão socializadora, fazendo com que a pessoa se sinta parte de uma comunidade de leitores com referências e cumplicidades múltiplas. (COLOMER, 2007, p. 143)

A abordagem numa dimensão socializadora demanda mais do professor, que enquanto mediador (a) conheça as obras que vai trabalhar, para promover discussões mais proveitosas. Para Tinoco e Stefhani (2006), na mediação há o aprendizado mútuo, em que alunos e professores são coparticipantes no ensino e aprendizagem. As experiências pessoais dos sujeitos interferem na interação e também no espaço das discussões, instigando mudanças, cooperação e empatia entre os sujeitos.

\section{A leitura literária no ensino médio: experiências com a poesia de Augusto dos Anjos}

Com o objetivo de investigar a recepção da poesia de Augusto dos Anjos no ensino médio e suas possíveis contribuições para formação de leitores, desenvolvemos uma intervenção ${ }^{3}$ do tipo pesquisa - ação, em uma turma de terceiro ano do ensino médio, de uma escola pública de Campina Grande. A turma era composta de vinte alunos e desse total, dezessete participaram das atividades.

Como professora pesquisadora, e, portanto, visitante na escola, planejamos a intervenção a partir da observação da turma e análise de um questionário ${ }^{4}$, que aplicamos na sala de aula, para sondar os interesses e práticas de leituras dos alunos. Elaboramos um plano de trabalho ${ }^{5}$ que contemplava três antologias temáticas, que tratavam do amor, natureza, vida e morte na poesia augustiana.

A antologia relacionada à natureza ${ }^{6}$ era constituída dos poemas "Vozes da morte", "A árvore da serra", "O pântano", "Minha árvore", "As montanhas", "A noite", "O mar" e "Plenilúnio". A temática escolhida estava dentro do horizonte de expectativas dos alunos, conforme podemos detectar no questionário, no qual os participantes citaram filmes e poemas que traziam o assunto. Além disso, os textos selecionados apresentavam uma visão mística e

\footnotetext{
${ }^{3}$ A intervenção na sala de aula foi desenvolvida em dez aulas.

${ }^{4} \mathrm{O}$ questionário era constituído de dez questões (múltipla escolha e aberta) que incidiam sobre interesses de leituras, gêneros literários mais lidos, livros, filmes e vídeos que faziam parte da vivência dos participantes. Além da leitura de poesia, inclusive dos poemas de Augusto dos Anjos.

${ }^{5} \mathrm{O}$ plano de trabalho integrava três módulos temáticos, cada um abordava uma antologia temática e propostas de atividades de leitura. O material pode ser consultado em: http://posle.ufcg.edu.br/index.php?title=2018.

${ }^{6}$ Nesse trabalho nos deteremos a essa antologia.
} 
panteística da natureza, enviesados pelo pessimismo e determinismo dos elementos que a integram. Com níveis de dificuldade que possibilitavam posturas mais reflexivas e dialógicas favorecendo a discussão e o debate.

Partimos das considerações de Colomer (2007), acerca da leitura compartilhada como possibilidade de construção de sentidos, pois a prática proporciona prazer, pelas trocas e discussões de experiências entre leitor - texto. Nessa perspectiva, alunos e professores podiam aprender juntos, se beneficiar das competências dos outros. Experimentar os momentos de interação, se perceber como integrantes de uma comunidade de leitores, o que auxilia na formação.

Como professora mediadora, procuramos favorecer um ambiente propício ao diálogo, nos colocando como parceira na aprendizagem, para construir o conhecimento a partir das colocações dos alunos, conforme defende Tinoco e Sthefani (2016).

Apresentamos nesse trabalho, a recepção dos poemas "Vozes da morte" e "O pântano", pois esses textos repercutiram nos leitores, que se mostraram entusiasmados e participativos. Os poemas foram abordados em uma aula, pois eram textos curtos e tínhamos um prazo para permanecer na turma, no entanto toda, a intervenção, compreendeu um período de dez aulas.

\subsection{Os poemas: "Vozes da morte" e "O pântano"}

Em "Vozes da morte" temos uma espécie de devaneio e fusão do eu lírico e o pé de tamarindo (planta recorrente na poesia do paraibano), em que as vozes causam uma espécie de alucinação. $\mathrm{O}$ eu poético reflete sobre a existência comparando a condição humana com a condição divina e grandiosa da natureza, que pode se multiplicar na terra pelas sementes. A velhice causa à degradação dos tecidos do homem e da árvore, numa "ultrafatalidade" inevitável, que leva a outra dimensão. Pertencentes a espécies diferentes, mas integrantes desse universo o eu lírico fica reduzido à condição finita da existência, enquanto que a planta continua a viver. Vejamos:

\section{VOZES DA MORTE}

Agora sim! Vamos morrer, reunidos, Tamarindo de minha desventura,

$\mathrm{Tu}$, com o envelhecimento da nervura, 
Eu, com o envelhecimento dos tecidos!

Ah! Esta noite é a noite dos Vencidos! E a podridão, meu velho! E essa futura Ultrafatalidade de ossatura,

A que nos acharemos reduzidos!

Não morrerão, porém, tuas sementes! E assim, para o Futuro, em diferentes Florestas, vales, selvas, glebas, trilhos,

Na multiplicidade dos teus ramos, Pelo muito que em vida nos amamos, Depois da morte, ainda teremos filhos! (ANJOS, Augusto. 1994. p. 234)

Já em "O pântano", também há um eu poético reflexivo que traz a natureza com o eixo das preocupações. No poema, esse espaço é transfigurado num grande túmulo que comporta o gênesis da existência. Vejamos:

\section{O PÂNTANO}

Podem vê-lo, sem dor, meus semelhantes!...

Mas, para mim que a Natureza escuto, Este pântano é o túmulo absoluto, De todas as grandezas começantes!

Larvas desconhecidas de gigantes Sobre o seu leito de peçonha e luto Dormem tranquilamente o sono bruto Dos superorganismos ainda infantes!

Em sua estagnação arde uma raça, Tragicamente, à espera de quem passa Para abrir-lhe, às escâncaras, a porta...

E eu sinto a angústia dessa raça ardente Condenada a esperar perpetuamente No universo esmagado da água morta! (ANJOS, Augusto dos. 1994. p. 314)

Observamos que o "túmulo absoluto" apresenta um caráter dual, pois ao mesmo tempo em que retém “as grandezas começantes”, também está à espreita de todos aqueles que a natureza, inclusive o homem, gerado por ela e que para ela retornará, pelo caráter cíclico da criação e existência.

\subsection{A recepção dos poemas}


A experiência com os poemas "Vozes da morte" e "O pântano" ocorreu no período de abordagem da antologia relacionada à natureza, tempo relativamente curto, mas que permitiu leituras significativas. A recepção dos textos nos chamou a atenção, pois estávamos numa sexta aula e os alunos logo que receberam o material demostraram interesse na leitura de "Vozes da morte", expondo atração sobre o título, que passou a ser alvo de brincadeiras na sala de aula:

Aluna A: E haja poema! "Vozes da morte". Eita, eu quero ler esse. Olha a voz da morte!

Turma de alunos: Eita. Eita. Eita.

Turma de alunos: Risos.

Aluna A: (Lendo o poema em voz alta). Eu já gostei desse.

Aluna D: Eu também.

Aluna B: Eita, tu nem leu.

Aluna A: Eu acabei de ler, B. Posso ler o primeiro?

Mediadora: Eu queria que primeiro vocês fizessem uma leitura silenciosa.

Aluna A: Eu já fiz.

Aluno D: Calma.

Após essa primeira aproximação com o texto, solicitamos que os participntes realizassem uma leitura silenciosa, para depois propiciar a leitura oral e a leitura compartilhada, pois assim eles podiam se familiarizar mais com a linguagem, pensar sobre a realização do poema, perceber singularidades, imagens, belezas que podiam ser discutidas e rediscutidas posteriormente. Como afirma Pinheiro (2018, p. 32) a respeito da leitura oral dos poemas: “(...) é um instrumento importante para uma aproximação ao poema e, no contexto de sala de aula, quando bem realizada, pode despertar o interesse de muitos leitores".

Com a leitura oral, realizada pela aluna E, percebemos que a aluna A, que queria ler o texto no início da aula, começou a $\operatorname{rir}^{7}$, provavelmente pelo tom de brincadeira atribuído pela participante. Após esse momento, perguntamos a aluna (E), suas impressões sobre "Vozes da morte", que nos questionou sobre dois versos:

Aluna E: O que ele quis dizer com "o envelhecimento da nervura, / eu com envelhecimento dos tecidos!"?

Procurando chamar a atenção da turma sobre o tema da natureza a partir de uma perspectiva mais ampla, chamamos a atenção para a postura do eu lírico em relação à vida e à morte associada ao ser humano.

\footnotetext{
${ }^{7}$ Dentre as categorias de análise dos dados do nosso experimento com a poesia de Augusto dos Anjos no ensino médio, o riso foi algo recorrente nas leituras e recepções dos demais poemas que abordados em sala de aula.
} 
A aluna A, nos questionou sobre o vocabulário de "Vozes da morte", sobre o termo "Tamarindo", que foi respondido pela colega afirmando que "era uma planta". A partir dos comentários das alunas explicamos que essa árvore na poesia de Augusto dos Anjos era algo recorrente, como forma de estimular a reflexão da poesia do autor e o compartilhamento das experiências de leitura dos alunos. $\mathrm{O}$ aluno $\mathrm{F}$, destacou e comentou mais dois versos:

Aluno F: "E a podridão, meu velho! / E essa futura Ultrafatalidade/ de ossatura". Acho que a podridão é consequência da velhice. A consequência da morte é o amor. A velhice é futuro de qualquer um.

Observamos que o leitor, ao associar a decomposição da árvore à velhice, interpretou o amor causa da morte, a partir do processo de associação. A leitura subjetiva ${ }^{8}$ realizada pelo aluno $\mathrm{F}$ indicou que ele refletiu sobre a abordagem do poema vinculando à realidade, inclusive se colocando na situação tratada pelo autor, quando o participante F afirmou que "a velhice é o futuro de qualquer um". De acordo com Jouve (2013), dentre os aspectos que constituem a leitura, há a participação da subjetividade do leitor, pois existe a necessidade de colaboração pessoal do sujeito na atividade.

Como mediadora destacamos o tom reflexivo do eu poético em relação à humanidade e colocamos "Árvore da serra" na conversa, pela aproximação que o poema apresenta com "Vozes da morte". Já que o texto é constituído de diálogos, propomos a leitura oral por três leitores, numa perspectiva mais lúdica e expressiva. Houve entusiasmo dos participantes e logo exteriorizaram opiniões sobre "Árvore da serra":

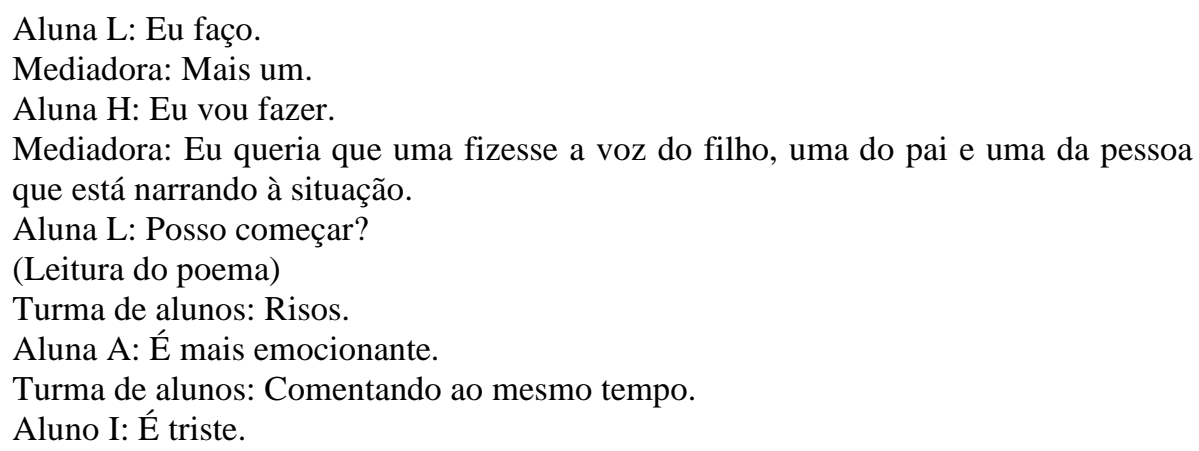

A participação da aluna L foi uma surpresa, já que ela estava muito calada nas aulas, mas atenta às discussões. Além disso, a participante disse em momento posterior, que não se

${ }^{8}$ A leitura subjetiva também foi uma das categorias escolhidas para a análise da recepção dos textos augustianos. 
expressava muito na sala de aula, pois tinha dificuldade, mas que nossa postura estimulou a ação, ressaltado nossa paciência e enfatizando o desejo dos outros professores agirem de forma parecida. A aluna A, destacou o tom emocionante de "Árvore da serra" e o aluno I, o tom triste do poema.

Estimulamos os leitores a observar aspectos mais formais dos textos ("Vozes da morte" e "Árvore da serra"):

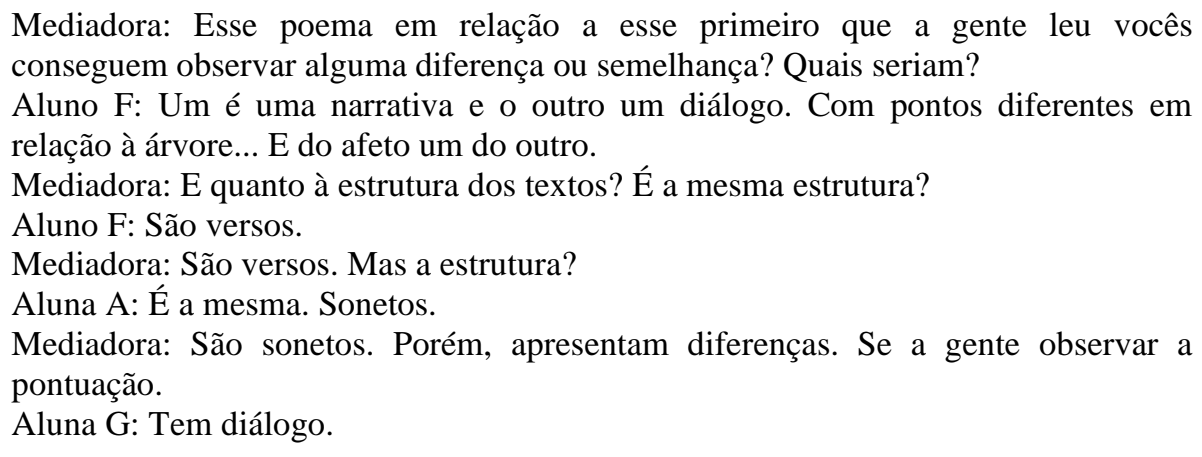

Considerando os vários sonetos da antologia, procuramos motivar os participantes a perceber a constituição diferenciada dos poemas, como por exemplo, o diálogo presente no soneto "Árvore da serra", destacado pelo aluno F, que também chamou atenção sobre a narrativa em "Vozes da morte".

A partir das observações dos alunos, chamamos a atenção sobre os recursos usados por Augusto dos Anjos como inovações da linguagem, uso de imagens da estética do feio, a semântica dos poemas, aludindo ao contexto histórico de publicação da obra e a repercussão nos críticos da época.

A turma passou a observar as particularidades da linguagem poética, como: rimas, repetições de palavras, a pontuação e fomos discutindo essas questões. Ressaltamos a musicalidade como recurso para a memorização dos textos, destacando a proximidade entre a poesia e a música.

Com “O pântano", seguimos a mesma metodologia. Após a leitura oral pelo aluno I, procuramos saber das impressões dos leitores. A participantes A, apontou "túmulo absoluto", sem comentar. O aluno $\mathrm{J}$ destacou os versos: "E eu sinto angústia dessa raça ardente/ Condenada a esperar perpetuamente/ No universo esmagado da água morta", agindo da mesma maneira que a aluna A. Os demais leitores permaneceram em silêncio. 
Notando a dificuldade da turma, sugerimos mais uma leitura e compartilhamos a nossa para estimular a discussão, destacando o tom reflexivo e as imagens associadas ao escuro, bem como da postura do eu poético sobre a natureza e a humanidade. A partir da associação desses recursos, motivamos os leitores a relacionar "O Pântano" a outros poemas já lidos:

\author{
Aluna A: não. Aqui é uma natureza morta. É uma natureza sem vida. \\ Aluna B: Morta. (Risos). \\ Aluna A: Mas é uma natureza morta! \\ Aluna B: No poema “Árvore da serra”. O pai mata a árvore...
}

Para a aluna A, a natureza na poesia de Augusto dos Anjos era morta, o que soou estranho para a leitora $B$, que riu da fala da colega, mas também destacou esse aspecto em “Árvore da serra". Outro leitor chamou atenção sobre o carácter atual dos textos e passamos a dialogar com exemplos.

No final da experiência pedimos para os alunos leitores avaliarem como foi a vivência com a poesia de Augusto dos Anjos. Procuramos explicitar, que eles podiam ser sinceros nos depoimentos e destacar particularidades positivas e negativas percebidas durante a intervenção. Vejamos como foi à experiência para o aluno D:

As aulas foram boas para refletirmos sobre a vida, pois ele fala muito sobre a morte,
a realidade. Na verdade nós sempre pensamos "o que será que eu estarei fazendo
daqui a dez anos?". Mas dificilmente pensamos no pior, sempre pensamos que
estaremos com um bom emprego, carro, etc. E ele fala sobre a morte, porém de uma
maneira comovente, fala de amor, e até da natureza, o que nos faz refletir, porque
sem a natureza não vivemos obviamente. Mas não damos muita importância para tal,
apreciamos o dinheiro, tecnologias e acabamos esquecendo do mais importante que
é a natureza e os animais que apesar de serem seres amáveis são maltratados,
retirados do seu habitat natural, aprisionados. (Aluno D, 2017)

Observamos que o leitor ressaltou o tema da morte como ponte para reflexão sobre a vida, no sentido que possibilitou uma perspectiva diferenciada. Notamos que houve atenção sobre questões referente à natureza, que foram relevantes e passaram a ser observadas sob outra ótica.

Para a aluna G, a vivência com a poesia de Augusto dos Anjos promoveu aproximação com o gênero, avaliando a experiências como "legais". Observe:

Foi uma experiência nova, porque comecei a me interessar mais por poesia. Para mim as aulas foram bem legais e tenho certeza que irei conhecer mais sobre poesia. (Aluna G, 2017) 
Segundo a leitora G, houve um estímulo e interesse sobre o texto poético, pois representou algo novo na sua formação, possibilitando inclusive "conhecer mais sobre poesia".

Os depoimentos dos alunos nos permitiu observar que houve interesse e aproximação entre texto e leitor, com destaque para a poesia. Ficamos entusiasmados, já que o gênero estava entre os textos menos lidos por esse público, como detectamos na análise do questionário aplicado em sala de aula.

\section{Considerações finais}

A experiência com os poemas augustianos permitiu aos alunos vivenciarem a leitura literária numa perspectiva de ensino que favorece a dimensão socializadora. Percebemos que houve momentos de dificuldades dos leitores de compartilhar as experiências com os textos. Nossa hipótese é de que isso tenha ocorrido devido a fatores de trajetória escolar dos alunos, pois em conversa com a professora da turma nos foi informado problemas de escrita e leitura dos participantes observados quando ela passou a ministrar aulas para eles.

Notamos várias reações na recepção, que possibilitou aproximação entre texto e leitor. Dentre as categorias (riso, estranhamento, leitura subjetiva e prazer) escolhidas para a análise dos dados, os poemas da natureza foram recebidos pela categoria do riso, muitas vezes causado pelo estranhamento das imagens, pelas dificuldades de pronúncia das palavras, pela linguagem e abordagem poética dos próprios textos.

Observamos as posturas reflexivas dos alunos, que também estiveram presentes na recepção e discussões da antologia, pois eles ficaram inquietos na apresentação das vivências. Além de verificamos leituras subjetivas.

Destacamos que a metodologia adotada favoreceu a participação, o diálogo e o compartilhamento de experiências, tornando as discussões mais dinâmicas e, contribuindo para que eles ficassem à vontade para discutir os textos.

Nesse sentido, a relação texto - leitor foi sendo construída, a partir da leitura dos poemas, das reflexões, dos diálogos, da atenção ao texto e das associações das experiências individuais, sociais.

Percebemos que o trabalho de mediação da leitura requer cuidados, nos impõe limites e dificuldades e para melhorarmos nossa prática de sala de aula precisamos ser leitores das 
obras e das teorias que nos auxiliem em nossas atividades. Para tanto, é de fundamental importância à formação continuada e sempre nos colocarmos em uma postura humilde diante do saber e do ensino, pois como professores não somos donos do conhecimento, sempre há algo a aprender na sala de aula, através das experiências vivenciadas, das colocações dos alunos, dos diálogos que estabelecemos com os jovens.

\section{Referências}

ANJOS, Augusto. Obra completa: volume único. Organização, fixação do texto e notas, Alexei Bueno. Rio de Janeiro: Nota Aguiar, 1994.

AGUIAR, Vera Teixeira de. BORDINI, Maria da Glória. Literatura: a formação do leitor: alternativas metodológicas. Porto Alegre: Mercado Aberto, 1988.

BRASIL. Orientações Curriculares para o Ensino Médio. Linguagens, Códigos e suas Tecnologias. Brasília. MEC/ Secretaria de Educação Básica, 2006.

CANDIDO, Antônio. A literatura e a formação do homem. In: Revista: Remate de Males. p. 81- 90. Dezembro de 2012. Disponível em: https://doi.org/10.20396/remate.v0i0.8635992. Acesso em: 24 de julho de 2018.

COLOMER, Teresa. Andar entre livros: a leitura literária na escola. [Tradução: Laura Sandroni]. São Paulo: Global, 2007.

COMPAGNON, Antoine. O leitor. In: $O$ demônio da teoria. Literatura e senso comum. Tradução de Cleonice Paes Barreto Mourão, Consuelo Fortes Santiago. 2. Ed. Belo Horizonte: editora UFMG, 2010. (p. 137-160)

DEBUS, Eliane. BAZZO, Jilvania Lima dos Santos. BORTOLOTTO, Nelita. Educação poética para infância e juventude: o que temos (ainda) a dizer?. In: Poesia (cabe) na escola: por uma educação poética. DEBUS, Eliane. BAZZO, Jilvania Lima dos Santos. BORTOLOTTO, Nelita. (orgs.). 1 ed. Campina Grande, PB: EDUFCG, 2018. p.7-16.

DIAS, Ana Crélia. Literatura e educação literária: quando a literatura faz sentido (s). Brasília: Revista Cerrados, vol. 25, $\mathrm{n}^{\circ}$ 42, p. 212-228. Dezembro de 2006. Disponível em: http://periodicos.unb.br/index.php/cerrados/issue/view/1776. Acesso: 23 de julho de 2019.

MARTINS, Ivanda. A leitura no ensino médio: quais os desafios do professor?. In: BUNZEN, Clécio. MENDONÇA, Márcia (orgs.). Português no ensino médio e formação do professor. São Paulo: Parábola Editorial, 2006. p. 83-102. 
Leitura literária e novas tecnologias: mudança de paradigmas. In: XX Jornada Nacional de Estudos Linguísticos (2. 2004: João Pessoa - PB). Anais [do] XX Jornada Nacional de Estudos Linguísticos em João Pessoa, no ano de 2004. João Pessoa, Idéia, 2004. P. 1111- 1120. Disponível em: <https://gelne.com.br/arquivos/anais/gelne2004/prin_total.htm.>. Acesso em: 23 de Janeiro de 2020.

PINHEIRO, Hélder. Poesia na sala de aula. 1. Ed. São Paulo: Parábola, 2018.

Práticas de língua e literatura no ensino médio: Olhares diversos, múltiplas propostas. Soélis Teixeira do Prado Mendes, Patrícia Aparecida Beraldo Romano (org.). Campina Grande: Bagagem, 2012.

Discutindo alternativas na formação de leitores. In: Memórias da Borborema 4: discutindo a literatura e seu ensino. ALVES, José Hélder Pinheiro (org.). Campina Grande: Abralic, 2014. p. 7- 18.

Reflexões sobre o livro didático de literatura. In: Português no ensino médio e formação do professor. In: BUNZEN, Clecio, MENDONÇA, Márcia (org). Português no ensino médio e formação do professor. São Paulo: Parábola, 2006. p. 103-116.

JAUSS, Hans Robert. A história da literatura como provocação à teoria literária. Trad. Sérgio Tellaroli. São Paulo: Ática, 1994.

JOUVE, Vicent. A leitura como retorno a si: sobre o interesse pedagógico das leituras subjetivas. In: Leitura subjetiva e ensino de literatura. [Trad. Neide Luzia de Rezende]. Org. ROUXEL, A.; LANGLADE, G.; REZENDE, N. L. São Paulo: Alameda, 2013. p. 53-65.

PETIT, Michèle. Leituras: do espaço íntimo ao espaço público. Trad. Cecília Olga de Souza. São Paulo: Editora 34, 2013.

REZENDE, Neide Luzia de. O ensino de literatura e a leitura literária. In: DALVI, Maria Amélia. REZENDE, Neide Luzia de. FALEIROS- JOVER, Rita. (orgs.). Leitura de literatura na escola. São Paulo, SP: Parábola, 2013.

ROUXEL, Annie. Ensino de literatura: experiência estética e formação do leitor. In: Memórias da Borborema 4: discutindo a literatura e seu ensino. ALVES, José Hélder Pinheiro (org.). Campina Grande: Abralic, 2014. p. 99-112.

Aspectos metodológicos do ensino de literatura. In: DALVI, Maria Amélia. REZENDE, Neide Luzia de. FALEIROS- JOVER, Rita. (orgs.). Leitura de literatura na escola. São Paulo, SP: Parábola, 2013. p. 17-33.

TINOCO. Robson coelho. STEFHANI. Adriana Demite. Leitura literária e papel do professor mediador no diálogo texto- leitor. In. Panorama contemporâneo em ensino das pesquisas em literatura. PINTO. Francisco neto Pereira. MELO. Márcia Araújo de. (org.). Campina Grande: ADUFCG, 2016. p. 83-114. 
WOOLF, Virginia. A paixão da leitura. In: $O$ sol e o peixe: prosas poéticas. [seleção e tradução Tomaz Tadeu]. 1. ed. 2. reimp. Belo Horizonte: Autêntica Editora, 2016. p. 35-39.

Recebido em 31 de agosto de 2019 Aceito em 20 de abril de 2020 